\title{
Técnicas persuasivas de comunicação em comerciais de alimentos para o telespectador brasileiro
}

\author{
Lucas Paulo Rigoni ${ }^{1}$ \\ Luciana Karine de Souza ${ }^{1}$ \\ Keitiline R. Viacava ${ }^{2}$ \\ Lisiane Bizarro ${ }^{1}$ \\ ${ }^{1}$ Universidade Federal do Rio Grande do Sul, RS, Brasil \\ ${ }^{2}$ Decision Making Lab (DM.Lab), RS, Brasil
}

\begin{abstract}
Resumo
O telespectador é exposto a grande quantidade de mensagens que buscam persuadi-lo a escolher um determinado produto. A elevada proporção de propagandas de alimentos não saudáveis pode influenciar hábitos alimentares e contribuir para a obesidade. O objetivo deste estudo foi identificar técnicas persuasivas de comunicação em propagandas de alimentos não saudáveis veiculadas na televisão. Uma amostra de 19 comerciais foi analisada em busca das técnicas persuasivas referidas na literatura. As técnicas mais frequentes foram conveniência, qualidade, sabor, valorização social e diversão. Também foram identificadas elevação do humor, oferta premiada, personagens animados e saudável, frequentes nos resultados de estudos nacionais e internacionais. Os resultados reforçam a pertinência do estudo psicológico das técnicas persuasivas, contribuindo para programas voltados a indivíduos que enfrentam problemas de saúde como obesidade, diabetes ou hipertensão. Podem, também, colaborar para ações preventivas para educar e conscientizar a população para a importância de escolhas mais conscientes e, possivelmente, saudáveis.
\end{abstract}

Palavras-chave: Propaganda; Alimento; Comunicação persuasiva.

\section{Communication persuasive techniques in food commercials for the Brazilian audience}

\begin{abstract}
Television audience is exposed to a large amount of messages aiming at persuasion to choose a particular product. The high proportion of unhealthy food advertisements can influence eating habits and contribute to obesity. The objective of this study was to identify communication persuasive techniques in advertisements for unhealthy foods on open television. Persuasive techniques reported in the literature were searched in 19 advertisements from Brazilian TV. The most frequent techniques found were convenience, quality, taste, social value, and fun. Mood elevation, award-winning offer, animated characters, and health appeal were also observed, consistent with results of previous studies. These results reinforce the pertinence of the psychological study of persuasive techniques. Identification of such techniques can contribute to programs aimed at individuals facing health problems such as obesity, diabetes or hypertension. They can also support preventive actions to educate the population about the importance of more conscious and, possibly, healthy choices.
\end{abstract}

Keywords: Propaganda; Food; Persuasive communication.

\section{Técnicas persuasivas de comunicación en anuncios de alimentos para el telespectador brasileño}

\section{Resumen}

El espectador se expone a una gran cantidad de mensajes que buscan persuadirle a elegir un determinado producto. La elevada proporción de propagandas de alimentos no saludables puede influir en los hábitos alimentarios y contribuir a la obesidad. El objetivo de este estudio fue identificar técnicas persuasivas de comunicación en propagandas de alimentos no saludables vehiculados en la televisión abierta en Brasil. Una muestra de 19 anuncios fue analizada en busca de las técnicas persuasivas referidas en la literatura. Las técnicas más frecuentes fueron conveniencia, calidad, sabor, valorización social y diversión. También se identificaron elevación del humor, oferta premiada, personajes animados y saludables, frecuentes en los resultados de estudios nacionales e internacionales. Los resultados refuerzan la pertinencia del estudio psicológico de las técnicas persuasivas, contribuyendo a programas dirigidos a individuos que enfrentan problemas de salud como obesidad, diabetes o hipertensión. Pueden también colaborar para acciones preventivas para educar y concientizar al público para la importancia de elecciones más conscientes y, posiblemente, saludables.

Palabras clave: Propaganda; Alimento; Comunicación persuasiva. 


\section{Introdução}

A elevada proporção de propagandas comerciais de alimentos não saudáveis na televisão (TV) é considerada um dos vários fatores de risco para a obesidade (David et al., 2016; Maia et al., 2017). Trata-se de comerciais sobre alimentos com quantidade elevada de açúcar, sódio, gordura saturada, gordura trans e bebidas com baixo teor nutricional (Keller, \& Schulz, 2011; Milani, Garlet, Romero, \& Mattos, 2015; Vilaro, Barnett, Watson, Merten, \& Mathews, 2017). De fato, a exposição repetida a esses comerciais estimula hábitos alimentares não saudáveis, como observado em estudos com crianças (Boyland et al., 2011), adolescentes (Mekhmoukh, Chapelot, \& Bellisle, 2012) e adultos (Scully, Dixon, \& Wakefield, 2009).

A publicidade de alimentos para o público infantil tem sido tema de mais de 80 projetos de lei no Congresso Nacional, bem como de diversos estudos científicos (Martins, 2014). O Instituto Brasileiro de Defesa do Consumidor (IDEC) disponibilizou uma publicação especial bilíngue português-inglês sobre a publicidade de alimentos não saudáveis. Aliado a isso, diversos institutos e organizações não governamentais têm se dedicado ao tema, a exemplo do Instituto Alana e seu Programa Criança e Consumo. Este programa "recebe denúncias de publicidade abusiva dirigida às crianças e atua por meio de ações jurídicas, pesquisa, educação e advocacy, influenciando a formulação de políticas públicas e o amplo debate na sociedade civil" (http://alana.org.br/project/crianca-e-consumo/).

Foi em virtude desse quadro que em 2010 a Agência Nacional de Vigilância Sanitária (ANVISA) publicou a Resolução RDC no 24/2010, estabelecendo normas para a divulgação e a promoção comercial de alimentos não saudáveis. Dentre outros aspectos, a Resolução solicitava que a propaganda veiculasse um alerta sobre o perigo do consumo excessivo de algum nutriente. No entanto, em 2013 o Juízo Federal da 16 a Vara da Seção Judiciária do Distrito Federal condenou a ANVISA a se abster de aplicar a Resolução 24/2010 aos associados da Associação Brasileira das Indústrias da Alimentação. Segundo argumentado, a Constituição Federal contempla a propaganda comercial de tabaco, bebidas alcoólicas, agrotóxicos, medicamentos, mas não menciona a alimentação.

Em 2014 o Conselho Nacional dos Direitos da Criança e do Adolescente (CONANDA) publicou a Resolução 163/2014, a qual dispõe sobre o abuso do direcionamento da publicidade e da comunicação mercadológica à criança e ao adolescente. Nessa resolução, é claramente vedada a publicidade que pretende persuadir crianças e adolescentes a consumir um dado produto ou serviço, recorrendo à condição vulnerável, ingênua, imatura e susceptível à sugestão, própria do público infanto-juvenil. Não obstante o próprio CONANDA admite que a Resolução 163/2014 não possui força de lei. Na mesma época da publicação da resolução, nove associações das áreas da publicidade e mídia (dentre elas, a Associação Brasileira de Emissoras de Rádio e Televisão, a Associação Brasileira de Rádio e Televisão, e a Associação Brasileira de TV por Assinatura) se manifestaram contra o documento.

O Guia Alimentar para a População Brasileira (Brasil, 2014) alerta sobre a influência deletéria que a publicidade exerce sobre as escolhas alimentares das pessoas. Segundo o guia, "a publicidade de alimentos ultraprocessados domina os anúncios comerciais de alimentos, frequentemente veicula informações incorretas ou incompletas sobre alimentação e atinge, sobretudo, crianças e jovens" (p. 117). Trata-se, portanto, de um tema de alta relevância social. Pesquisas científicas podem contribuir também para fundamentar leis que regulamentem a publicidade de alimentos não saudáveis no país.

Uma explicação para os efeitos dos comerciais de alimentos sobre o comportamento alimentar está no uso de técnicas persuasivas de comunicação (ou técnicas persuasivas, para resumir), comumente adotadas nas campanhas de marketing (Hebden, King, \& Kelly, 2011). No caso do marketing dirigido a crianças, por exemplo, é comum o uso de personagens de ficção, desenhos ou animação gráfica (Neeley \& Schumann, 2004), muitas vezes derivados de programas assistidos pelas crianças (Hebden et al., 2011). Dentre as técnicas persuasivas mais utilizadas estão oferta premiada, a ênfase a aspectos do produto considerados saudáveis pelo anunciante, o destaque ao sabor e também à diversão (Jenkin, Madhvani, Signal, \& Bowers, 2014; Kelly, Hattersley, King, \& Flood, 2008).

Em um estudo que analisou o uso de técnicas persuasivas em 87 comerciais, $28 \%$ destes incluiu celebridades e $26 \%$ destacaram preço ou promoções. Quanto ao contexto das propagandas, a maioria incluiu imagens de casas $(72,4 \%)$, seguida por lojas $(20,7 \%)$ e ambientes ao ar livre (6,9\%) (Sixsmith \& Furnham, 2010). Do total de comerciais, 59\% deles foram considerados direcionados ao público em geral, ou seja, sem distinção etária. Sixsmith e Furnham (2010) ressaltaram a dificuldade de identificação da faixa etária alvo da propaganda. A este respeito, Harris, Bargh e Brownell (2009) concluíram que o consumidor pode ser afetado pelo comercial a despeito da faixa etária pretendida para o público-alvo. Dessa forma, os dois estudos apresentam dados que apoiam que análises do conteúdo e do uso de técnicas persuasivas 
em comerciais sejam realizadas sem a obrigatoriedade da distinção etária do público-alvo.

Há também técnicas persuasivas que frisam aspectos como fome ou vontade de comer, agressão, raiva, tédio e solidão. Pettigrew, Roberts, Chapmann, Quester e Miller (2012) analisaram 93.284 comerciais de alimentos, dos quais 14.611 utilizavam essa técnica. Provavelmente temas negativos sejam escolhidos porque já foi demonstrada uma associação positiva entre humor negativo e direcionamento da atenção para alimentos (Hepworth, Mogg, Brignell, \& Bradley, 2010). Por outro lado, a técnica elevação do humor é bastante frequente nas propagandas comerciais de alimentos, mostrando a comida como estratégia para melhorar o humor (Pettigrew et al., 2012).

Outra questão que demonstra a relevância de estudos dedicados à análise de técnicas persuasivas usadas em comerciais de alimentos é a necessidade de salvaguardar os consumidores do efeito conhecido como health halo (Chandon, \& Wansink, 2012). Trata-se da tendência em superestimar a salubridade de um produto com base em uma única característica. De acordo com esse modelo, o consumidor elabora inferências a partir de informações incompletas sobre um determinado produto (seu sabor, qualidade ou benefícios à saúde). Ao mesmo tempo, precisa lidar com motivações hedônicas diante de suas escolhas de consumo. Nesse sentido, é possível que a presença de técnicas persuasivas, como o uso de elementos visuais, apelos ao produto e apelos emocionais, promova o efeito health halo, influenciando as intenções do consumidor (Chandon, \& Wansink).

No Brasil, há pesquisas que avaliam o conteúdo das propagandas de alimentos veiculadas na TV. Maia et al. (2017), ao analisarem 2732 comerciais veiculados na TV aberta, identificaram que $61 \%$ das propagandas sobre alimentos e bebidas tratavam de alimentos ultraprocessados e, portanto, não saudáveis. Todavia os autores não investigaram as técnicas persuasivas utilizadas nestes comerciais.

Já Britto, Viebig e Morimoto (2016) focalizaram no público infantil ao analisarem 1618 comerciais veiculados em seis canais de TV a cabo. Do total de comerciais, 190 tratavam de alimentos e bebidas, dos quais 139 envolviam alimentos ultraprocessados (73\%). Retiradas as repetições, 14 comerciais de diferentes produtos foram identificados e analisados conforme os parâmetros propostos pelo Guia Alimentar para a População Brasileira (Brasil, 2014) e a Resolução 163/2014 do CONANDA. Nove comerciais envolveu o uso de personagens ou linguagem infantis, seis utilizou músicas infantis e/ou cantadas por crianças e três incluíram a oferta premiada. O trabalho de
Britto et al. (2016) abordou estratégias de persuasão presentes nas propagandas, mas sem contemplar a literatura especializada sobre técnicas persuasivas. Ademais, a pesquisa focalizou no telespectador infantil de TV paga, tendo gravado os comerciais durante as férias escolares do mês de julho - ou seja, em período propício à veiculação de propagandas de produtos direcionados a crianças.

Apesar das evidências relevantes dos estudos brasileiros anteriores, não foram localizadas pesquisas que identificassem e descrevessem as técnicas persuasivas utilizadas em propagandas de alimentos não saudáveis no Brasil veiculadas em canais abertos de TV, sem delimitar a idade do público-alvo. Assim, o objetivo do presente estudo foi identificar as técnicas persuasivas nas propagandas comerciais de alimentos não saudáveis veiculadas na programação da TV aberta brasileira.

\section{Método}

\section{Amostra}

A amostra foi composta por 19 propagandas comerciais provenientes de um banco de dados com 81 DVDs. O banco foi criado pela equipe de pesquisa a partir da gravação simultânea da programação de três canais nacionais de TV aberta. As gravações foram realizadas no Brasil, durante a primeira quinzena de junho de 2013. Esse período foi determinado por ser considerado relativamente neutro quanto a efeitos de marketing sazonal, os quais envolvem eventos como Natal, Carnaval, Páscoa, Dia das Mães ou férias escolares.

As 19 propagandas foram escolhidas por critério de maior frequência dentre as 720 veiculações observadas como propagandas de alimentos. Todas as propagandas comerciais selecionadas foram previamente classificadas como de produtos não saudáveis, segundo o Guia Alimentar para a População Brasileira (Brasil, 2014). Os três canais abertos selecionados para as gravações foram os de maior audiência da TV brasileira no período, segundo o ranking global divulgado pelo Instituto Brasileiro de Opinião Pública e Estatística (IBOPE, 2013) - o instituto líder na aferição de audiência de TV e Rádio no Brasil e na América Latina.

\section{Procedimentos de Análise dos Dados}

Para a identificação e descrição dos dados que apontam o uso de técnicas persuasivas nos 19 comerciais televisivos selecionados, dois passos de análise foram seguidos. A análise iniciou com os pesquisadores assistindo aos vídeos e realizando descrições dos mesmos, com base no entendimento 
de descrição qualitativa fundamental de Sandelowski (2000). Em seguida, foi conduzida a codificação baseada em conceitos (Gibbs, 2009). Este tipo de codificação parte de categorias ou conceitos obtidos a partir da literatura e/ou de estudos anteriores similares. Três grupos de técnicas persuasivas utilizadas em propagandas de alimentos foram selecionados da literatura: elementos visuais (EV), apelos ao produto (AP), e apelos emocionais (AE) (Hebden et al., 2011).

O grupo EV contemplou três técnicas: (a) contexto (lugar, ambiente ou paisagem de anúncio do produto), (b) celebridades (pessoa famosa, popular da TV, música, esporte) e (c) personagens animados (personagens de animação gráfica, desenhos animados) (Boyland et al., 2011; Greenberg, Rosaen, Worrell, Salmon, \& Volkman, 2009; Harrison, \& Marske, 2005; Hebden et al., 2011; Keller, \& Schulz, 2011; Kelly et al., 2008, 2010; Neeley, \& Schumann, 2004; Sixsmith, \& Furnham, 2010).

Para o grupo AP foram selecionadas sete: (a) conveniência (fácil de obter, portar e/ou preparar, prático), (b) qualidade (de melhor qualidade que o concorrente, provê bem-estar, é natural, orgânico, com os melhores ingredientes), (c) economia (vale o preço ou seu decréscimo, tornando-ocompetitivonomercado),(d)inovação (novo, diferente, moderno), (e) sabor (foco no gosto/palatabilidade, é saboroso, há prazer no sabor), (f) saudável (benéfico à saúde, com valor nutricional, ausência/redução de nutrientes indesejados) e (g) oferta premiada (a compra vem com prêmio, às vezes igual ao produto anunciado) (Boyland et al., 2011; Boyland, Harrold, Kirkham, \& Halford, 2012; Harris et al., 2009; Harrison, \& Marske, 2005; Hebden et al., 2011; Keller, \& Schulz, 2011; Kelly et al., 2008, 2010; Sixsmith, \& Furnham, 2010).

O grupo AE contou com 14: (a) elevação do humor (consumo/aquisição do produto eleva o humor, provê emoções positivas voltadas a comportamentos adaptativos), (b) diversão (verbalização de diversão/ alegria, pessoas sorrindo, divertindo-se), (c) autoconfiança (consumo/aquisição aumenta a autoconfiança), (d) conquista de objetivo (consumo/aquisição traz conquistas/realizações), (e) triunfo (temática de vitória ou de tornar-se herói/heroína), (f) atração física/beleza (aumento/conservação da beleza física), (g) satisfação (consumo alivia fome, sede ou outro desconforto), (h) energia (consumo fornece energia), (i) esporte (pessoas em atividade física/esporte, melhora no desempenho físico), (j) fantasia versus realidade (personagens, situações ou eventos imaginários, irreais, fantásticos), (1) interação pais-filhos (aumenta essa interação), (m) valorização social (consumo em grupo, aproxima os amigos), (n) romance (roman- tismo, carinho entre casais) e (o) aventura/surpresa (atividades aventurosas, acontecimentos surpreendentes/inesperados) (Bell, \& Dittmar, 2011; Boyland et al., 2012; Greenberg et al., 2009; Harris et al., 2009; Hebden et al., 2011; Keller, \& Schulz, 2011; Kelly et al., 2010; Pettigrew et al., 2012; Sixsmith, \& Furnham, 2010; Vieira, \& Bosi, 2013).

A análise foi conduzida com base nas 24 técnicas, ou categorias, conforme descrito. A única categoria que não foi analisada conforme sua presença ou ausência no comercial foi a categoria contexto.

Dois avaliadores categorizaram $25 \%$ da amostra de vídeos para averiguação dos critérios de heterogeneidade (diferentes entre si) e homogeneidade (semelhança quanto ao conteúdo que cada uma abriga) das categorias. Constatado o respeito aos critérios, o restante da amostra foi analisado pelo primeiro autor do presente texto. Utilizou-se uma tabela para registro da presença/ausência de 23 categorias. O contexto (ou contextos) mostrado nas propagandas é referido na descrição dos comerciais.

\section{Resultados}

Primeiramente são apresentadas descrições breves dos comerciais analisados, as quais iniciam com a indicação do contexto abordado na propaganda. Em seguida, é relatada a frequência de ocorrência das demais 23 técnicas analisadas.

\section{Descrição dos Comerciais}

Iogurte (Comercial $1=\mathrm{C} 1)$. No quarto de dormir, uma mulher pergunta à outra sobre a pilha de roupas na cama, a qual responde não conseguir decidir qual usar, porque está desconfortável. A primeira fala que isso não é normal e apresenta o iogurte, que, por substâncias específicas, desincha o estômago e elimina o desconforto. Uma animação gráfica mostra uma explicação científica sobre o processo do alimento no corpo. As duas mulheres bebem o iogurte, e aquela que estava desconfortável sorri. O comercial termina convidando o telespectador a comprovar a eficácia participando do "desafio": o dinheiro será devolvido caso não fique satisfeito.

Suco de caixinha (C2). Na escola, duas crianças tiram um suco de caixinha da mochila e o tomam. Aparecem engajados em atividades como corrida, salto, skate, penduram-se em uma corda, etc. A menina tira a embalagem da mochila, insere um canudinho e bebe. Nas atividades, há cenas em paralelo das crianças como personagens animados fazendo as mesmas atividades. O pai vai buscar as crianças. No carro, ele pergunta se estão cansadas. Elas negam entusiasticamente, o 
pai olha pelo retrovisor e vê os personagens animados no lugar dos filhos. Aparece na tela que o suco foi desenvolvido com a colaboração de nutricionistas.

Biscoito integral (C3). Na cozinha, uma mulher está saindo para trabalhar, e diz ao homem que o dia será muito ocupado. Ele mostra que preparou um café da manhã especial com o produto anunciado. Os dois consomem o produto durante a propaganda. $\mathrm{O}$ homem lê em voz alta que o produto possui vitaminas, cereal "integral" e é fonte de energia para ajudar a "encarar o dia agitado". A palavra energia surge na tela e uma voz fala que o produto oferece "energia para o dia-a-dia". A mulher prova o biscoito, demonstra gostar e fala que é "uma delícia", demonstrando humor positivo. $\mathrm{O}$ comercial termina com um beijo rápido do casal.

Sanduíche de hambúrguer (C4). No parque, com muitas árvores e gramado, um rapaz está sentado em um banco com seu cachorro. Um homem aparece, carregando seu lanche, sem precisar de pratos, mesa ou talheres. O rapaz fica olhando o homem prestes a comer um hambúrguer. A câmera focaliza o homem e há sons de respiração ofegante se movendo na sua direção. Aparece o rapaz pulando sobre o homem, tentando pegar o sanduíche de suas mãos. No final, o sanduíche aparece em close, um narrador fala de seu sabor, ingredientes e que na compra de uma combinação específica de produtos o consumidor ganha um sorvete "grátis".

Biscoito salgado (C5). Um rapaz entra em um ônibus e senta-se ao lado de uma moça acompanhada de um aparente namorado. Ela rapidamente olha para o rapaz. Ele puxa da mochila um pequeno pacote de biscoitos e começa a comê-los. Um narrador fala que o produto é "inconfundível". A moça e o rapaz começam a trocar mensagens sublinhando trechos nos livros que carregam abertos sobre o colo. A moça escreve no texto do rapaz o seu número de telefone, e desce do ônibus.

Refrigerante original (C6). Nas ruas de uma cidade, jovens fazem esportes e colorem paredes cinza. O refrigerante está associado ao tema de um evento de futebol. As latas do refrigerante aparecem coloridas. Os jovens estão sempre correndo e dançando, com música em compasso rápido. $\mathrm{O}$ produto está sempre com os jovens, que o bebem enquanto andam de bicicleta, ajudam-se e comemoram algo.

Salgadinho original (C7). Na festa em uma casa, todos ouvem música, conversam, enquanto comem o salgadinho, demonstrando-se divertir enquanto o consomem. Um jovem aparece seminu e pula na piscina, constrangendo muitos dos presentes na cena. Um narrador fala que, se for para dividir alguma coisa, que divida o produto nomeado.
Maionese original (C8). Em diferentes contextos, uma voz feminina pergunta a algumas pessoas sobre como utilizam maionese e qual marca preferem. As pessoas descrevem como preparam suas receitas, demonstrando satisfação com a inclusão do produto nelas. As pessoas aparecem comendo a maionese com muita satisfação. Todos preferem a marca anunciada. No final, a voz fala que esta é a "verdadeira" maionese.

Chocolate pequeno (C9). Durante o intervalo de aula, um rapaz tem em mãos uma embalagem de chocolates pequenos. Oferece um para uma menina, que sorri ao virar e enxergar o rapaz, aceitando o doce. $\mathrm{Na}$ tela, surgem frases com as palavras ousadia, galera, amizades e possibilidades. O narrador argumenta que a vida pode ter mais dessas coisas, enquanto reaparece o rapaz, que parece tímido junto de outros jovens. Em seguida, o chocolate aparece bem grande, ocupando quase toda a tela, mostrando como ele é fabricado. Os jovens aparecem comendo e demonstrando muito prazer. Ouve-se que o chocolate é mais crocante e gostoso.

Ketchup (C10). Esse comercial dura cinco segundos, em contexto indefinido. Uma mão abre a tampa de uma embalagem de ketchup, que aparece em close, coloca-o em um sanduíche e fecha. Um narrador fala o nome da marca e diz que "ninguém é melhor".

Caldo de carne (C11). Na cozinha, uma mulher prepara alimentos e um homem aparece e os prova. A mulher o afasta com um tapinha leve na mão e os dois se mostram felizes. A mulher mostra é fácil de preparar, pois com poucos movimentos a pessoa o prepara. Uma narradora diz que o produto mantém o caldo da carne e que "passou no teste" (já que o homem provou e demonstrou gostar). $\mathrm{O}$ almoço chega pronto à mesa, ao redor da qual há pais (os protagonistas) e filhos, demonstrando satisfação, brincando e sorrindo. $\mathrm{O}$ produto está no meio da cena. A narradora pede para que o telespectador faça o teste.

Caldo de frango (C12). Na cozinha, familiares observam o frango assando no forno. Uma mulher entra em cena e pergunta se eles não haviam planejado sair. Um narrador fala, e repete ao longo do comercial, que com um frango "suculento assim" ninguém vai querer sair de casa. O termo "suculento" é repetido, o produto aparece em close. Inicia um pequeno filme do processo de preparo: "é fácil de fazer", diz o narrador, enquanto a mãe prepara e a filha observa e sorri. No encerramento, anuncia-se que o dinheiro será devolvido caso a qualidade prometida não condiga com aquela exaltada na propaganda.

Chocolate em barra (C13). No avião, o piloto aparece abrindo o produto, mordendo-o e exibindo satisfação. Os passageiros passam a flutuar, em clima 
de diversão, brincam, olham-se, sorriem um para o outro e dividem o chocolate.

Fastfood (C14). No apartamento, dois estudantes jogam videogame, quando um terceiro entra na cena com o pacote de comida a ser anunciada. Os três conversam sobre algo engraçado, o produto aparece e um narrador o descreve como boa sugestão, barato e gostoso. Todos concordam com a boa sugestão, que pagar menos e economizar é "genial". Há um contexto de comédia, com risadas ao fundo, semelhante ao formato de séries de TV.

Café em pó (C15). Na cozinha, um pai prepara café para a filha. Além do sabor, ouve-se falar do cheiro e da temperatura do produto, além de a palavra café estar sempre acompanhada do nome da marca. O modo de preparo é mostrado como fácil. O pai observa a filha provar e espera sua reação, sorrindo ao ver que ela sorri.

Bebida láctea (C16). Em um contexto urbano, de cidade, com prédios, um jovem caminha sem rumo claro, com o produto nas mãos e bebendo-o enquanto anda. Há obstáculos no caminho. O rapaz pula e faz movimentos caracterizando um contexto de aventura. Pega um elevador e chega ao topo de um prédio. Pula para alcançar uma nova garrafinha de bebida láctea. Há um tema de fantasia durante toda a propaganda.

Margarina (C17). Uma mãe e seu filho mais novo estão sentados à mesa com alimentos típicos de café da manhã. Conversam por computador com webcam com outro filho, mais velho, que está em outro país. A mãe abre o pote do produto e o passa no pão. O filho mais velho está comendo uma comida exótica para brasileiros, e pede para passar o produto na comida que ele está comendo, estendendo a mão para a tela, dizendo que poderia ficar melhor. A mãe orienta que o filho se alimente, depois balança a mão com o produto e diz: "Vem tomar café da manhã direito". Um narrador fala que a qualidade de vida começa com o produto anunciado. Um personagem animado aparece junto ao produto.

Queijo (C18). Rapidamente e em contexto indefinido, o produto aparece em close, junto com pães. Uma pessoa come um sanduíche com o queijo da marca anunciada, mas não se vê seu rosto. Um narrador diz que as pessoas devem pedir o queijo pelo nome (fala o nome da marca), porque dessa marca "é mais gostoso".

Sanduiche (C19). No restaurante, pessoas aparecem comendo um sanduíche. Imagens bastante ampliadas, com foco nas mordidas ao produto. Um narrador refere que é "gostoso", esta palavra surge na tela e, muito rapidamente, a palavra "saudável". Por fim, é dito que quem faz uma boa escolha é porque escolhe este produto.

Duas propagandas se desenvolveram em contexto indefinido (C10 e C18), e uma em mais de um contexto (C8). As demais 16 ocorreram em um único contexto ou principalmente em um, conforme segue: (a) cozinha (C3, C11, C12 e C15), (b) outros espaços domésticos (quarto de dormir, sala de jantar ou copa, pátio, sala de estar) (C1, C7, C14 e C17), (c) escola (C2 e C9), (d) espaços urbanos (ruas e edifícios) (C6 e C16), (e) meios de transporte (ônibus, avião) (C5 e C13), (f) restaurante $(\mathrm{C} 19)$ e $(\mathrm{g})$ parque $(\mathrm{C} 4)$.

\section{Técnicas persuasivas utilizadas na amostra}

No conjunto de 19 propagandas comerciais de alimentos analisadas, foram identificadas 106 ocorrências classificadas como possivelmente persuasivas. Excluiu-se desta contagem a categoria contexto, como referido anteriormente.

Das 106 ocorrências analisadas, as técnicas de $\mathrm{EV}$ foram detectadas quatro vezes. $\mathrm{O}$ grupo de $\mathrm{AP}$, ao total, obteve 50 ocorrências. Já o grupo de AE gerou 52 ocorrências. A única técnica não identificada na amostra foi atração física/beleza.

A Tabela 1, adiante, mostra as cinco técnicas persuasivas mais frequentes, acompanhadas de exemplos. As três mais frequentes são do grupo AP: conveniência, qualidade e sabor. Em seguida, figuram duas técnicas AE: valorização social e diversão.

Como mostra a Tabela 1, em 15 dos 19 comerciais foi identificada a técnica persuasiva que apela à conveniência em preparar, consumir ou portar o produto anunciado. Já em 13 propagandas foi possível averiguar o apelo à qualidade. Em 11 comerciais identificou-se a técnica que apela ao sabor do alimento. As técnicas $\mathrm{AE}$ mais utilizadas recorreram à: valorização social, presente em nove comerciais, e diversão, em oito comerciais.

As frequências das demais técnicas identificadas foram iguais ou menores que cinco. Essas frequências, ausentes na Tabela 1, são relatadas e ilustradas a seguir.

A técnica saudável foi observada em cinco comerciais, como no caso de C3: rapaz lê a embalagem; o produto contém vitaminas e é feito com cereais integrais. As seguintes técnicas obtiveram quatro ocorrências cada: (a) inovação (o produto é referido como novo e associado a um jeito diferente de "curtir a vida" - C9), (b) satisfação (consumidora se alivia de desconforto estomacal ao consumir o produto C1), (c) aventura/surpresa (protagonista passa por um cenário instável, aventurando-se - C16), (d) interação pais-filhos (pai prepara para a filha um café da marca referida, ambos desfrutam de um momento juntos e ficam felizes - C15), (e) autoconfiança (garoto porta o produto e parece obter confiança para se aproximar de menina - C9), (f) romance (há um flerte - C5) e (g) conquista de objetivo (garoto consegue a atenção de uma menina, portando o produto - C9). 
TABELA 1

Técnicas Persuasivas de Comunicação para Análise de Comerciais de Alimentos

\begin{tabular}{|c|c|c|}
\hline Grupo & Técnica & Descrição da técnica \\
\hline \multirow[t]{3}{*}{ Elementos visuais } & Contexto & Lugar, ambiente ou paisagem em que o produto é anunciado \\
\hline & Celebridades & Pessoa famosa, bem conhecida, popular da TV, música, esporte \\
\hline & Personagens animados & Personagens de animação gráfica, desenhos animados \\
\hline \multirow[t]{7}{*}{ Apelos ao Produto } & Conveniência & Fácil de obter ou preparar, prático \\
\hline & Qualidade & $\begin{array}{l}\text { De melhor qualidade que a concorrência, provê bem-estar como um todo; "natural", } \\
\text { "orgânico", "com os melhores ingredientes" }\end{array}$ \\
\hline & Economia & Vale o preço ou seu decréscimo, tornando-o competitivo no mercado \\
\hline & Inovação & Novo, diferente, moderno \\
\hline & Sabor & Focaliza gosto/palatabilidade; saboroso, há prazer no sabor \\
\hline & Saudável & Benefícios à saúde; valor nutricional, ausência/redução de nutrientes indesejados \\
\hline & Oferta premiada & A compra vem com prêmio, podendo ser igual ao anunciado \\
\hline \multirow[t]{14}{*}{ Apelos Emocionais } & Elevação de humor & Consumo/aquisição eleva humor, provê emoções positivas para ações adaptativas \\
\hline & Diversão & Verbalização de diversão/alegria; pessoas sorrindo, divertindo-se \\
\hline & Autoconfiança & Consumo/aquisição aumenta a autoconfiança \\
\hline & Conquista de objetivo & Aquisição/consumo traz conquista/realização \\
\hline & Triunfo & Temática de vitória ou de tornar-se herói/heroína \\
\hline & Atração física/beleza & Aumento/conservação da beleza física \\
\hline & Satisfação & Consumo alivia fome, sede ou outro desconforto \\
\hline & Energia & Consumo fornece energia \\
\hline & Esporte & Pessoas em atividade física/esporte; melhora no desempenho físico \\
\hline & Fantasia $\times$ realidade & Personagens, situações ou eventos imaginários, irreais, fantásticos \\
\hline & Interação pais-filhos & Aumenta a interação pais-filhos \\
\hline & Valorização social & Consumo em grupo ou engaja mais os amigos \\
\hline & Romance & Romantismo, romance, carinho entre casais \\
\hline & Aventura/Surpresa & Atividades aventurosas, acontecimentos surpreendentes/inesperados \\
\hline
\end{tabular}

Nota: Criado por Rigoni, Souza, Viacava e Araújo, 2017, a partir da literatura (Bell \& Dittmar, 2011; Boyland et al., 2011, 2012; Greenberg et al., 2009; Harris et al., 2009; Harrison \& Marske, 2005; Hebden et al., 2011; Keller \& Schulz, 2011; Kelly et al., 2008, 2010; Neeley \& Schumann, 2004; Pettigrew et al., 2012; Sixsmith \& Furnham, 2010; Vieira \& Bosi, 2013).

Duas técnicas foram observadas três vezes: elevação do humor (atriz fica mais alegre quando sabe do produto - C3) e fantasia versus realidade (há um paralelo entre o mundo real e outro fantasioso - C2). Quatro técnicas foram identificadas por duas vezes: (a) personagens animados (personagens de animação gráfica de desenho infantil - C2), (b) celebridades (atores de novelas da TV brasileira consomem o produto - C3), (c) esporte (jovens aparecem praticando esportes e a marca é associada ao futebol - C6) e (d) energia (ator comenta que o produto vai proporcionar energia - C3). As seguintes técnicas foram observadas por uma vez na amostra: (a) economia (o produto é sugerido como uma forma de pagar menos C14), (b) oferta premiada (anuncia-se que, em devida circunstância, o consumidor receberá um bônus - C4) e (c) triunfo (crianças consomem o produto, realizam feitos e são reconhecidas $-\mathrm{C} 2$ ).

\section{Discussão}

O objetivo deste estudo foi analisar propagandas comerciais de alimentos dentre as mais frequentes na programação da TV brasileira, identificando e descrevendo como aparecem as técnicas persuasivas que possam influenciar comportamentos e hábitos alimentares. Foram identificadas 106 ocorrências do uso de técnicas persuasivas nas 19 propagandas analisadas. Em média, observou-se o uso de aproximadamente cinco técnicas persuasivas por propaganda comercial. Esse resultado é consistente com estudos anteriores sobre o tema (Hebden et al., 2011; Jenkin et al., 2014; Kelly et al., 2008), e corrobora com a hipótese de que o marketing de alimentos pode promover efeitos de health halo (Chandon, \& Wansink, 2012) ao superestimar (ou subestimar) certas características dos produtos a partir do uso de técnicas persuasivas. 
As três técnicas de elementos visuais apontadas pela literatura foram identificadas na amostra. Esse resultado é convergente com pesquisas prévias, nas quais o uso de personagens animados foi apontado como uma das técnicas comumente utilizadas nas propagandas de alimentos não saudáveis (Jenkin et al., 2014; Kelly et al., 2008; Neeley, \& Schumann, 2004), especialmente naquelas direcionadas a crianças (Britto et al., 2016; Sixsmith, \& Furnham, 2010). Especificamente quanto ao contexto, notou-se uma preferência pelo ambiente doméstico para a propaganda de alimentos não saudáveis (cozinha, sala, quarto) resultado similar ao de Sixsmith e Furnham (2010), que detectaram maior uso de imagens de residências nos comerciais.

Também é digno de nota o apelo ao contexto escolar, próprio para atingir o público infanto-juvenil. Ademais, surpreende o uso do contexto de um parque, com largo gramado e muitas árvores, para anunciar um sanduíche de hambúrguer acompanhado de um gratuito sorvete - alimentos ultraprocessados, muito desejados e, portanto, consumidos por crianças, adolescentes e adultos com excesso de peso e risco para obesidade. Outras técnicas acompanharam o comercial referido, como a elevação do humor (Pettigrew et al., 2012) e a oferta premiada (Boyland et al., 2011, 2012), o que ilustra o potente arsenal aplicado para influenciar o consumidor. Como referem David et al. (2016), trata-se de um marketing agressivo e perverso.

Do grupo de técnicas de apelos ao produto, destacaram-se conveniência, qualidade e sabor, resultado semelhante a estudos anteriores (Hebden et al., 2011; Jenkin et al., 2014; Kelly et al., 2010). Oferta premiada também foi identificada, em consonância com o estudo conduzido por Britto et al. (2016). Convém observar que o apelo ao sabor foi uma das técnicas mais usadas nos comerciais de alimentos voltados ao público infantil (Jenkin et al., 2014), e também esteve presente em mais da metade das propagandas analisadas em outra pesquisa do gênero (Hebden et al.).

Quanto aos apelos emocionais, o apelo à diversão é uma das técnicas persuasivas mais presentes nas propagandas (Hebden et al., 2011; Jenkin et al., 2014). A diversão parece estar ligada ao consumo automático de guloseimas (i.e., consumo sem intenção ou com baixo controle), observado tanto em crianças como em adultos (Harris et al., 2009). Como já comentado, a elevação do humor também foi identificada, em especial após o emparelhamento (Todorov, 1985) com imagens negativas (Pettigrew et al., 2012).

Do conjunto das propagandas comerciais analisadas, uma das questões subjacentes parece ser o uso do tempo. São de elevado valor as escolhas que envolvem rapidez, conveniência, praticidade. Chegar mais rápido a um destino, carregar menos peso por maior distância, dispor facilmente de algo em quase qualquer lugar, enfim, ações associadas à economia de tempo para que este seja ocupado com outras atividades, muito provavelmente provedoras de recompensas. Nesse contexto, as propagandas de alimentos não saudáveis acabam seguindo essa tendência e apresentam o produto como capaz de economizar tempo, ser prático e conveniente. Estes são apelos importantes do produto para um consumidor ávido pelos valores rapidez, praticidade e conveniência.

Outra tendência observada foi a busca generalizada pelo prazer. Há um elevado apelo para a qualidade do produto, para a diversão associada, o sabor, tudo mediante muitos sorrisos, risadas, piadas e/ ou flerte. Em sua análise sobre o prazer no comer e suas implicações para o vício alimentar, Sawaya e Filgueiras (2013) destacam o poder dos alimentos e bebidas recompensadores. Nesses alimentos, a mistura de açúcar, gordura e sal 'em doses 'certas' tem efeito somatório na geração de prazer” (p.59). Os autores argumentam a grande influência, sobre a decisão de comprar, da "informação de que teremos uma experiência prazerosa e recompensadora ao adquirir aquele produto, até chegar a dizer que ingeri-lo nos fará 'felizes"” (p.59). Trata-se do tipo de informação, como se buscou demonstrar no presente estudo, utilizada nas técnicas persuasivas. Como argumentado anteriormente, é o caminho do mínimo esforço e da máxima recompensa (maior prazer) com o mínimo de tempo investido - uma equação esteve bastante presente nos comerciais de alimentos não saudáveis analisados.

Também é notório o emparelhamento de alimentos não saudáveis com imagens e ideais de inteligência, esperteza, sucesso nas relações românticas ou de amizade, ganho de novidades no cotidiano, aumento da autoestima e sucesso profissional (especialmente com a economia de tempo). Todas essas questões são emparelhadas com a alimentação não saudável no comercial. Em tempos de economia de tempo (esta redundância é proposital), buscar resolver problemas socioemocionais via alimentação parece uma solução mais conveniente, rápida e saborosa do que engajar em atividades de lazer, entretenimentos sociais e/ou psicoterapia.

Outro aspecto comum nas propagandas de alimentos não saudáveis é seu emparelhamento com algo saudável. Alguns produtos são mostrados em contextos de natureza, com pessoas realizando exercícios, ou com frutas, verduras e outros alimentos saudáveis ao redor. Aliado a isso está a falta de informação sobre o alimento 
ou seus resultados a médio/longo prazo após ingestão. As imagens são mais diretas e comunicam mais fortemente com o consumidor, no lugar de explicações e detalhamentos. Todavia por vezes a questão não está em o que é mostrado, mas em o que não é. A falta de conhecimento sobre informações sobre os ingredientes do alimento, ou sobre os efeitos de sua ingestão, é uma questão ética saliente na propaganda de alimentos não saudáveis. Um dos princípios que norteou a elaboração do Guia Alimentar para a População Brasileira preconiza que a educação para a alimentação saudável deve ser acompanhada não apenas das informações sobre alimentos benéficos à saúde, mas também sobre as estratégias que as propagandas utilizam para distorcer ou omitir aspectos indesejáveis dos alimentos não saudáveis (Brasil, 2014).

David et al. (2016) avaliam as estratégias de proteção contra o marketing de alimentos não saudáveis que vêm sendo utilizadas por governos, fundações e até movimentos sociais. Os autores organizam as estratégias em três grupos: campanhas informativas, movimentos contrapropaganda e advertências sanitárias. Nas campanhas informativas, tem-se observado que uma abordagem mais criativa (como utilizar nomes divertidos para alimentos saudáveis pouco atraentes do ponto de vista de uma criança) colabora mais para mudanças nos hábitos alimentares. Outro exemplo referido por David et al. é o guia alimentar, cujo maior desafio é transmitir conhecimento em linguagem compreensível à população em geral. Já os movimentos contrapropaganda são raros, embora tenham demonstrado impacto notável no contraponto, por exemplo, à indústria tabagista. Este mesmo quadro se aplica às advertências sanitárias, as quais, como referido na introdução, no Brasil recebem apoio através de recomendações (ANVISA, 2010; CONANDA, 2014); todavia não possuem força de lei.

$\mathrm{Na}$ forma de guia alimentar, movimento contrapropaganda ou advertência sanitária, é possível contrapor o peso dos comerciais de alimentos não saudáveis na TV com as mesmas técnicas persuasivas utilizadas pela indústria de alimentos nas propagandas.
Por exemplo, no movimento contrapropaganda, como sugerem David et al. (2016), a união das pessoas insatisfeitas com o marketing agressivo de alimentos ultraprocessados proporciona a inclusão dessas pessoas que, como minoria, possuem pouca oportunidade de se manifestar. De posse dessa sugestão, parece pertinente considerar o uso da técnica valorização social, que trata da aceitação do sujeito em um grupo de pessoas, para atrair consumidores insatisfeitos a se engajarem em movimentos sociais na contramão do marketing pró-alimentos ultraprocessados. As outras técnicas também podem contribuir para os movimentos contrapropaganda, bem como para as advertências sanitárias em rótulos e as campanhas governamentais (inclusive veiculadas na TV).

No presente estudo, a idade do público que assiste a comerciais de alimentos na TV não foi controlada, nem comparada quanto à distribuição das propagandas comerciais analisadas. Futuros estudos podem considerar este aspecto, bem como gênero e nível socioeconômico. Tais variáveis são interessantes no que diz respeito aos efeitos de identificação entre o público consumidor e as pessoas que atuam em comerciais de alimentos, nas quais podem se espelhar.

Por fim, a veiculação de propagandas comerciais de alimentos não saudáveis é uma questão de saúde relevante, ainda que não diretamente de interesse maior das políticas públicas da área. Os alarmantes índices de obesidade em nível mundial e brasileiro mostram a pertinência de se monitorar as ações que influenciam o comportamento alimentar da população. No que diz respeito a investimentos em saúde pública, ações preventivas, de tipo educativo, podem economizar grandes quantias aos cofres públicos, considerando-se os gastos já empenhados com o tratamento de doenças crônicas advindas da alimentação não saudável. Nessas ações preventivas cabem o monitoramento e regulamentação dos comerciais de alimentos não essenciais à saúde, e o estudo psicológico das propagandas tem muito a contribuir cientificamente para este caminho.

\section{Referências}

Agência Nacional de Vigilância Sanitária. (2010). Resolução RDC no 24, de 15 de junho de 2010. Brasília, DF, Brasil.

Bell, B., \& Dittmar, H. (2011). Does Media Type Matter? The Role of Identification in Adolescent Girls' Media Consumption and the Impact of Different Thin-Ideal Media on Body Image. Sex Roles, 65(7-8), 478-490. https:// doi.org/10.1007/s11199-011-9964-X

Boyland, E., Harrold, J., Kirkham, T., Corker, C., Cuddy, J., Evans, D., ..., \& Halford, J. (2011). Food commercials increase preference for energy-dense foods, particularly in children who watch more television. Pediatrics, 128(1), E93-E100. https://doi.org/10.1542/peds.2010-1859 
Boyland, E., Harrold, J., Kirkham, T., \& Halford, J. (2012). Persuasive techniques used in television advertisements to market foods to UK children. Appetite, 58(2), 658-664. https://doi.org/10.1016/j.appet.2011.11.017

Brasil. Ministério da Saúde. Secretaria de Atenção à Saúde. Departamento de Atenção Básica. (2014). Guia Alimentar para a População Brasileira (2aㅡ ed.). Brasília: Ministério da Saúde.

Britto, S., Viebig, R., \& Marimoto, J. (2016). Analysis of food advertisements on cable television directed to children based on the food guide for the Brazilian population and current legislation. Revista de Nutrição (Campinas), 29(5), 721-729. https://doi.org/10.1590/1678-98652016000500010

Chandon, P. \& Wansink, B. (2012). Does food marketing need to make us fat? A review and solutions. Nutrition Reviews, 70(10). https://doi.org/10.1111/j.1753-4887.2012.00518.x

Conselho Nacional dos Direitos da Criança e do Adolescente. (2014). Resolução no 163, 13 de março de 2014. Presidência da República. Secretaria de Direitos Humanos. Retrieved from http://dh.sdh.gov.br/download/ resolucoes-conanda/res-163.pdf

David, I. A., Krutman, L., Andrade, J., Araújo, R., Braga, F., Gomes, F., ..., \& Volchan, E. (2016). Pistas implícitas e obesidade: estratégias de proteção contra o marketing de alimentos. Demetra: Alimentação, Nutrição \& Saúde, 11(2), 383-398. https://doi.org/10.12957/demetra.2016.21777

Gibbs, G. (2009). Análise de dados qualitativos. Porto Alegre: Penso.

Greenberg, B., Rosaen, S., Worrell, T., Salmon, C., \& Volkman, J. (2009). A Portrait of Food and Drink in Commercial TV Series. Health Communication, 24(4), 295-303. https://doi.org/10.1080/10410230902889233

Harris, J., Bargh, J., \& Brownell, K. (2009). Priming effects of television food advertising on eating behavior. Health Psychology, 28(4), 404-413. https://doi.org/10.1037/a0014399

Harrison, K., \& Marske, A. (2005). Nutritional content of foods advertised during the television programs children watch most. American Journal of Public Health, 95(9), 1568-1574. https://doi.org/10.2105/AJPH.2004.048058

Hebden, L., King, L., Chau, J., \& Kelly, B. (2011). Food advertising on children's popular subscription television channels in Australia. Australian and New Zealand Journal of Public Health, 35(2), 127-130. https://doi.org/10.1111/ j.1753-6405.2011.00610.x

Hebden, L., King, L., \& Kelly, B. (2011). Art of persuasion: An analysis of techniques used to market foods to children. Journal of Paediatrics and Child Health, 47(11), 776-782. https://doi.org/10.1111/j.1440-1754.2011.02025.x

Hepworth, R., Mogg, K., Brignell, C., \& Bradley, B. (2010). Negative mood increases selective attention to food cues and subjective appetite. Appetite, 54(1). https://doi.org/10.1016/j.appet.2009.09.019

Instituto Brasileiro de Opinião Pública e Estatística. (2013). Audiência da televisão brasileira. Retrieved from http:// www.ibope.com.br

Jenkin, G., Madhvani, N., Signal, L., \& Bowers, S. (2014). A systematic review of persuasive marketing techniques to promote food to children on television. Obesity Reviews, 15(4), 281-293. https://doi.org/10.1111/obr.12141

Keller, S., \& Schulz, P. (2011). Distorted food pyramid in kids programmes: A content analysis of television advertising watched in Switzerland. European Journal of Public Health, 21(3), 300-305. https://doi.org/10.1093/ eurpub/ckq065

Kelly, B., Halford, J., Boyland, E., Chapman, K., Bautista-Castano, I., Berg, C., ... Summerbell, C. (2010). Television food advertising to children: A global perspective. American Journal of Public Health, 100(9), 1730-1736. https:// doi.org/10.2105/AJPH.2009.179267

Kelly, B., Hattersley, L., King, L., \& Flood, V. (2008). Persuasive food marketing to children: use of cartoons and competitions in Australian commercial television advertisements. Health Promotion International, 23(4), 337-344. https://doi.org/10.1093/heapro/dan023

Maia, E., Costa, B., Coelho, F., Guimarães, J., Fortaleza, R., \& Claro, R. (2017). Análise da publicidade televisiva de alimentos no contexto das recomendações do Guia Alimentar para a População Brasileira. Cadernos de Saúde Pública, 33(4), e00209115. https://doi.org/10.1590/0102-311x00209115

Marins, B., de Araujo, I., \& Jacob, S. (2011). Food advertising: advice or merely stimulation of consumption? Ciencia \& Saude Coletiva, 16(9), 3873-3882.

Martins, A. P. B. (Org.) (2014). Publicidade de alimentos não saudáveis: os entraves e as perspectivas de regulação no Brasil. Cadernos IDEC (Série Alimentos - Vol. 2). São Paulo: IDEC.

Mekhmoukh, A., Chapelot, D., \& Bellisle, F. (2012). Influence of environmental factors on meal intake in overweight and normal-weight male adolescents. A laboratory study. Appetite, 59(1), 90-95. https://doi.org/10.1016/j. appet.2012.03.021

Milani, M., Garlet, L., Romero, G., \& Mattos, K. (2015). Influência da mídia nos hábitos alimentares de crianças: uma revisão da literatura. Revista de Epidemiologia e Controle de Infecção, 5(3), 153-157. https://doi.org/10.17058/reci. v5i3.5115

Neeley, S. \& Schumann, D. (2004). Using animated spokes-characters in advertising to young children - Does increasing attention to advertising necessarily lead to product preference? Journal of Advertising, 33(3), 7-23. https://doi.org/ 10.1080/00913367.2004.10639166

Pettigrew, S., Roberts, M., Chapman, K., Quester, P., \& Miller, C. (2012). The use of negative themes in television food advertising. Appetite, 58(2), 496-503. https://doi.org/10.1016/j.appet.2011.12.014 
Sandelowski, M. (2000). Whatever happened to qualitative description? Research in Nursing \& Health, 23, 334-340. https://doi.org/10.1002/1098-240X(200008)23:4<334::AID-NUR9>3.0.CO;2-G

Sawaya, A. \& Filgueiras, A. (2013). "Abra a felicidade”? Implicações para o vício alimentar. Estudos Avançados, 27(78), 53-70. https://doi.org/10.1590/S0103-40142013000200005

Scully, M., Dixon, H., \& Wakefield, M. (2009). Association between commercial television exposure and fast-food consumption among adults. Public Health Nutrition, 12(1), 105-110. https://doi.org/10.1017/S1368980008002012

Sixsmith, R. \& Furnham, A. (2010). A content analysis of British food advertisements aimed at children and adults. Health Promotion International, 25(1), 24-32. https://doi.org/10.1093/heapro/dap045

Todorov, J. C. (1985). O conceito de contingência tríplice na análise do comportamento humano. Psicologia: Teoria e Pesquisa, 1(1), 75-88. Retrieved from https://revistaptp.unb.br/index.php/ptp/article/view/1116/233

Vieira, C. \& Bosi, M. (2013). Corpos em confecção: considerações sobre os dispositivos científico e midiático em revistas de beleza feminina. [Making bodies: considerations on scientific and media devices in women's beauty magazines]. Physis: Revista de Saúde Coletiva, 23(3), 843-861. https://doi.org/10.1590/S0103-73312013000300010

Vilaro, M., Barnett, T., Watson, A., Merten, J., \& Mathews, A. (2017). Weekday and weekend food advertising varies on children's television in the USA but persuasive techniques and unhealthy items still dominate. Public Health, 142, 22-30. https://doi.org/10.1016/j.puhe.2016.10.011

Dados dos autores:

Lucas Paulo Rigoni - Psicólogo, Universidade Federal do Rio Grande do Sul.

Luciana Karine de Souza - Doutora, Universidade Federal do Rio Grande do Sul.

Keitiline R. Viacava - Doutora, Decision Making Lab (DM.Lab).

Lisiane Bizarro - Doutora, Universidade Federal do Rio Grande do Sul.

Endereço para correspondência:

Luciana Karine de Souza

Rua Ramiro Barcelos, 2600, sala 102 - Bairro Santana

90035-006 Porto Alegre, RS, Brasil

<lukarides@gmail.com>

Recebido em: 29.06.2017

Aceito em: 10.01.18 